\title{
THE 1981 UNITED NATIONS REPORT: AN HISTORICAL CONSENSUS ON THE SAFE USE OF NUCLEAR POWER SOURCES IN SPACE
}

\author{
Gary L. Bennett \\ Propulsion, Power and Energy Division \\ National Aeronautics and Space Administration \\ Code RP \\ Washington, D. C. 20546 \\ (202) 453-2856
}

\begin{abstract}
In 1981, after over three years of study and discussion, the technical specialists in the United Nations Committee on the Peaceful Uses of Outer Space agreed to a report which provided general safety criteria; a suggested format for notification for reentering space vehicles containing nuclear power sources; suggested improvements in orbit prediction; and recommendations relating to the search and recovery of a nuclear power source. The results of that first consensus on the use of nuclear power sources are summarized to provide an historical framework for developing international norms on the use of nuclear power sources in outer space.
\end{abstract}

\section{INTRODUCTION}

Following the 1978 reentry of the Soviet radar ocean reconnaissance satellite (RORSAT) known as Cosmos 954 over Canada the United Nations (U.N.) took up the question of the use of nuclear power sources (NPS) in outer space. Over the years most of the action has centered on the U.N. Committee on the Peaceful Uses of Outer Space (COPUOS) and its two standing subcommittees of the whole: the Scientific and Technical Subcommittee (STSC) and the Legal Subcommittee (LSC). A general logic was established that a technical Working Group on the Use of Nuclear Power Sources in Outer Space (WGNPS) would be established in the STSC to consider the technical aspects and safety measures relating to the use of NPS in outer space with the results of the WGNPS studies being passed through the STSC to the LSC for its consideration and follow-up action as appropriate (Bennett et al. 1988a).

By way of background it is worth noting that COPUOS and its two subcommittees operate on the consensus principle rather than voting. As stated in Bennett et al. 1988a: "In effect, this means that any member or group of members can prevent COPUOS or its subcommittees from taking action on that topic by formally objecting to such action, whether that action consists simply of adopting a report containing the conclusions of COPUOS or its subcommittees or proposed principles. In practice, the achievement of consensus takes time. This is especially true in regard to topics that are highly scientific or technical in nature and where the science and technology 
are continuing to evolve... On the other hand, the consensus principle provides a firm and uniform basis of support for any resulting agreement."

In the wake of Cosmos 954, many delegations to the 1978 STSC and LSC meetings expressed concern about safety measures for NPS and notification prior to reentry. Uncertainties over predictions of the impact point for Cosmos 954 led a number of delegations to suggest a need for improved orbit prediction models. Several delegations, in particular some from developing countries, expressed a need for assistance in search and recovery should an NPS impact their territories. These concerns and interests became the focus for a number of national studies completed during the period from 1978 to 1981. Using these studies and other papers the WGNPS met formally in three sessions (1979, 1980, and 1981) and, at the conclusion of its third session in 1981, issued a report that represents the first technical consensus on the technical and scientific aspects relating to the use of NPS in space. As noted in Bennett et al. 1988a: "The U.S. delegation worked actively with the Canadian delegation and the other WGNPS delegations to achieve consensus on the safety and technical aspects of the 1981 WGNPS report in an effort to maintain the momentum toward the LSC. Consequently, the U.S. delegation has consistently supported the text of the 1981 report." The report was adopted by the STSC and the STSC report was accepted by COPUOS. In view of the ongoing discussions in the U.N. on the use of NPS in outer space as summarized most recently in Hodgkins et al. 1991 it is worth reflecting back upon that first technical consensus in order to provide an historical framework for future discussions of the use of NPS in space.

The following sections summarize the consensus views of the 1981 WGNPS report with regard to various aspects of the use of NPS in space, including the types of NPS, safety measures, notification of reentry, orbit prediction, and search and recovery. One of the most important parts of the 1981 WGNPS report was its conclusion (U.N. 1981):

\footnotetext{
"The Working Group reaffirmed its previous conclusion that NPS can be used safely in outer space, provided that all necessary safety requirements are met."
}

\section{TYPES OF NPS}

The 1981 WGNPS report begins by noting ". . . that various types of power sources exist for use on spacecraft such as solar cells, fuel cells and chemical batteries, as well as nuclear systems. Selection of a suitable power source is a complex technical issue and in practice most space missions have used conventional power sources. The particular advantages of the use of NPS are their long life, compactness and ability to operate independently of solar radiation." (U.N. 1981).

The 1981 WGNPS report then stated that "For certain important space missions NPS have been the preferred technical choice. Provided the additional risks associated with NPS are maintained at an acceptably low level, the Working Group considered that the basis of the decision to use NPS should be technical." (Emphasis added.) The WGNPS report 
dealt with two kinds of NPS: radioisotope generators and nuclear reactors (U.N. 1981).

The WGNPS report defined radioisotope generators as consisting ". . of radionuclide fuels surrounded by energy conversion systems. The radio-isotope decays spontaneously, emitting ionizing radiation which is absorbed as heat and can be converted into other forms of energy." The WGNPS report stated that nuclear reactors ". . . derive their thermal energy from the controlled fission of uranium 235. The reactor consists of an enriched uranium core with a reflector, producing heat for possible conversion to other forms of energy." (U.N. 1981). There

was no intention in the 1981 WGNPS report to limit nuclear reactors to ${ }^{235} \mathrm{U}$; rather, as stated in Bennett et al. 1988a: "Plutonium-239 reactors were not considered because there was no evidence that any nation was using them. A U. K. working paper, however, noted in comparison with ${ }^{235} \mathrm{U}$ that '. . . a plutonium fuelled reactor would be a somewhat greater risk, but it would take many times the five tonnes of plutonium dispersed in weapon tests before the hazard from fissile material could dominate." The source for the U.K statement may be found in U.N 1978.

The WGNPS report stated that "Both systems require that appropriate design and operational measures be taken, in order to protect the population and the environment for both normal and accidental conditions. Moreover the risks inherent in each particular application or project are to be assessed in terms both of the probability of failure or malfunction and the severity of its consequences." (U.N. 1981).

\section{SAFETY MEASURES}

The WGNPS report ". . . noted that the safety of radio-isotope systems was being assured by designing them to contain with a high probability of success the radio-isotope for normal and credible abnormal conditions." The report continued by stating that "The design should ensure minimal leakage of the radio-active contents with a reasonably high level of probability of success in all credible circumstances including launch accidents, re-entry into the atmosphere, impact and water immersion. The appropriate limits recommended by the International Commission on Radiological Protection (ICRP) should be met for normal operational conditions." (U.N. 1981).

Regarding nuclear reactors the WGNPS report stated that "The Working Group agreed that the safety of U-235 reactor systems did not present any difficulty when they were started and operated in orbits sufficiently high to give time for radio-active materials to decay to a safe level in space after the end of the mission. In this way the dose equivalents at the time of re-entry could be guaranteed in all circumstances to be within the limits recommended by ICRP for nonaccident conditions. If reactors are intended for use in low orbits where the radio-active materials do not have sufficient time to decay to an acceptable level, safety depends on the start of the operation in orbit and the success of boosting NPS to a higher orbit after operation is completed. In the event of an unsuccessful boost into higher orbit the system should in all credible circumstances be capable of dispersing the radio-active material so that when the material reaches the earth the radiological situation conforms to the recommendations of ICRP when relevant. The 
Working Group noted that ICRP publication 26 does not provide specific guidance for accidents and emergencies although it does address in general terms the circumstances in which remedial action might be taken." (U.N. 1981). Dispersal was agreed to in the 1981 report simply because that was the design approach being followed by both the U.S. and the U.S.S.R. at that time (Bennett and Buden 1983). Since 1981 the criterion for the SP-100 reactor has been changed to intact reentry so it is worth noting that in 1978 Canada had suggested intact reentry for reactors and in 1987 the Canadian delegation offered a working paper which stated that "Nuclear reactors shall be designed either to reenter to Earth's atmosphere and land while maintaining the functional integrity of the containment of radioactive materials, or to divide and disperse into fine particles the radioactive materials upon reentry into the Earth's atmosphere . . ." (Canada 1987 and U.N. 1978).

Throughout the deliberations leading up to the adoption of the 1981 WGNPS report there were discussions and working papers on applying various ICRP guidelines (including radiation dose limits) to NPS. The WGNPS recommended that the limits specified in ICRP publication 26 "... should not be exceed during normal phase of an NPS mission." However, the WGNPS was aware that in some accident cases the dose limits of ICRP publication 26 could be exceeded and so the WGNPS quoted ICRP publication 26 that "detailed guidance on the application of its recommendations, either in regulations or in codes of practice, should be elaborated by the various international and national bodies that are familiar with what is best for their needs." (U.N. 1981). Thus, the WGNPS report does not specify dose limits for accidents.

\section{NOTIFICATION}

The WGNPS report took note of the U.N. General Assembly (UNGA) resolution 33/16 ". . . which requests launching States to inform States concerned in the event that a space object with NPS on board is malfunctioning with a risk of re-entry of radio-active materials to the earth." (U.N. 1981). The report also states ". . that States should be informed of a possible re-entry or malfunctioning of a spacecraft carrying an NPS so that those concerned might take necessary precautionary measures. The earliest possible notification of such an occurrence is deemed essential." (U.N. 1981). The Working Group felt that the early notification should be to the Secretary-General of the United Nations. The WGNPS ". . . agreed to the following format of notification for re-entering space vehicles containing NPS which may give rise to radiological hazards:" (U.N. 1981)

\section{System parameters}

*1.1 Name of launching State or States including the address of the authority which may be contacted for additional information or assistance in case of accident

*1.2 International designation

*1.3 Date and territory or location of launch 


\subsection{Information required for best prediction of orbit lifetime, trajectory and impact}

region

\section{*1.5 General function of spacecraft}

\section{Informatien on the radiological risk of nuclear power source(s)}

\subsection{Type of NPS: radio-isotopic/reactor}

2.2 The probable physical form, amount and general radiological characteristics of the fuel and contaminated and/or activated components likely to reach the ground. The term "fuel" refers to the nuclear material used as the source of heat or power.

The asterisks denote the requirements contained in the Convention on Registration of Objects Launched into Outer Space. This convention, which entered into force on 15 September 1976, is generally referred to as the "Registration Convention". The above format has been adopted by COPUOS (Hodgkins et al. 1991).

\section{ORBIT PREDICTION}

The WGNPS was aware that reentry dates could only be predicted with an error of about 10 percent of the remaining lifetime and so ". . noted that prediction of orbit lifetimes and re-entry paths of uncontrolled satellites remains at best an inexact science." (U.N. 1981). The WGNPS stated that "Accuracy could be improved by the implementation of additional degrees of control, further research and study and by extensive and co-operative use of tracking stations and communications lines." (U.N. 1981).

\section{SEARCH AND RECOVERY}

In the WGNPS report "The Working Group recommended that assistance in training be provided through appropriate international channels to personnel of States requesting training on hazard evaluation following re-entry of an NPS and on performing pertinent search and recovery and emergency planning operations." (U.N. 1981).

The WGNPS goes on to state that "The Working Group noted that the Agreement on the Rescue of Astronauts, the Return of Astronauts and the Return of Objects Launched into Outer Space and the Convention of International Liability for Damage caused by Space Objects are of direct relevance to search and recovery questions relating to NPS. It noted in particular that under the first agreement a launching State is obliged, at the request of a State affected, to eliminate possible damage or harm that might result from the return of a space object or its component parts which is of hazardous or deleterious nature, and that, under the second agreement, a launching State is obliged to examine the possibility of rendering appropriate and rapid assistance to a State suffering damage caused by a space object which presents a large-scale danger to human life or seriously interferes with the living conditions of the population or the functioning of 
vital centres, when that State so requests." (U.N. 1981). A summary of the relevance of these and other treaties to the use of NPS in space has been provided in Bennett 1988b.

\section{CONCLUSIONS}

As noted in Hodgkins et al. 1991, the U.N. is continuing its deliberations on the use of NPS in outer space. The 1981 WGNPS report represents the first technical consensus achieved on technical aspects and safety measures and, as such, provides a useful historical framework for the ongoing deliberations. In this connection, the conclusion of the 1981 WGNPS report that ". . . the Working group reaffirmed its previous conclusion that NPS can be used safely in outer space, provided that all necessary safety requirements are met" represents not only a consensus of international technical experts but a succinct statement of the U.S. position as well.

\section{References}

Bennett, G. L. and D. Buden (1983) "Use of Nuclear Reactors in Space," The Nuclear Engineer, Vol. 24, No. 4, pp. 108-117.

Bennett, G. L., J. A. Sholtis, Jr., and B. C. Rashkow (1988a) "United Nations Deliberations on the Use of Nuclear Power Sources in Space: 1978 - 1987," in Space Nuclear Power Systems 1988, M. S. El-Genk and M. D. Hoover, eds., Orbit Book Co., Malabar, FL, pp. 45-57.

Bennett, G. L. (1988b) "Proposed Principles on the Use of Nuclear Power Sources in Space," IECEC Paper No. 889027, in Proceedings of the 23rd Intersociety Energy Conversion Engineering Conference, held in Denver, Colorado, 31 July-5 August 1988.

Canada (1987) "The Elaboration of Draft Principles Relevant to the Use of Nuclear Power Sources in Outer Space," Working Paper submitted by Canada to the Legal Subcommittee of the U.N. Committee on the Peaceful Uses of Outer Space, U.N. Document A/AC.105/C.2/L.154/Rev. 1, United Nations, 12 March 1987.

Hodgkins, K. D., R. Lange, and B. C. Rashkow (1991) "United Nations Consideration of the Use of Space Nuclear Power," in Proceedings of the Eighth Symposium on Space Nuclear Power Systems, CONF-910116, M. S. El-Genk and M. D. Hoover, eds., American Institute of Physics, New York, NY, 1991.

United Nations (1978) "Question Relating to the Use of Nuclear Power Sources in Outer Space, Report of the Secretariat," U.N. Document A/AC.105/220, United Nations, 20 May 1978.

United Nations (1981) "Report of the Working Group on the Use of Nuclear Power Sources in Outer Space on the Work of its Third Session," Annex II of Report of the Scientific and Technical Subcommittee on the Work of its Eighteenth Session, U.N. Document A/AC.105/287, United Nations, 13 February 1981. 
AIP CONFERENCE PROCEEDINGS 246

DOE CONF-920104

L.C. Catalog Card No. 91-58793

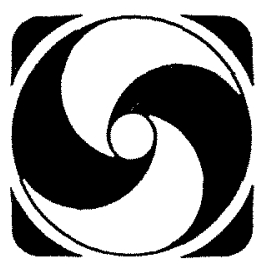

PROCEEDINGS

OF THE NINTH SYMPOSIUM

ON SPACE NUCLEAR POWER

SYSTEMS

\section{EDITORS}

Mohamed S. El-Genk

University of New Mexico

\author{
Mark D. Hoover \\ Inhalation Toxicology \\ Research Institute
}

INSTITUTE FOR SPACE NUCLEAR POWER STUDIES

Chemical and Nuclear Engineering Department

The University of New Mexico

Albuquerque, NM 87131

(505) $277-2813,277-2814$

Co-sponsored by:

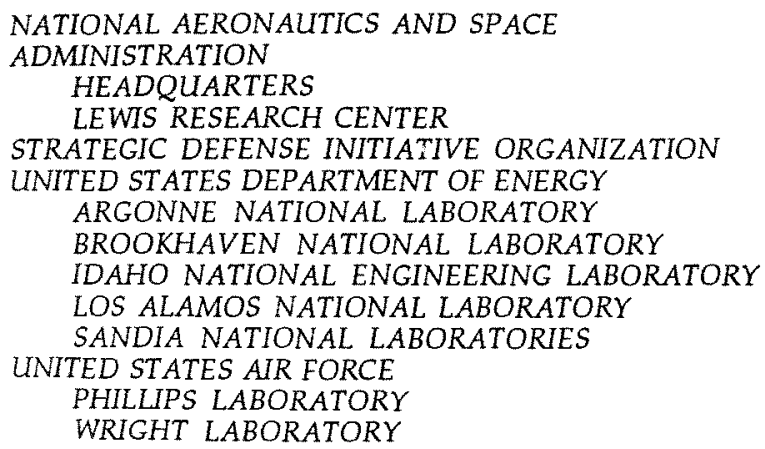

In cooperation with:

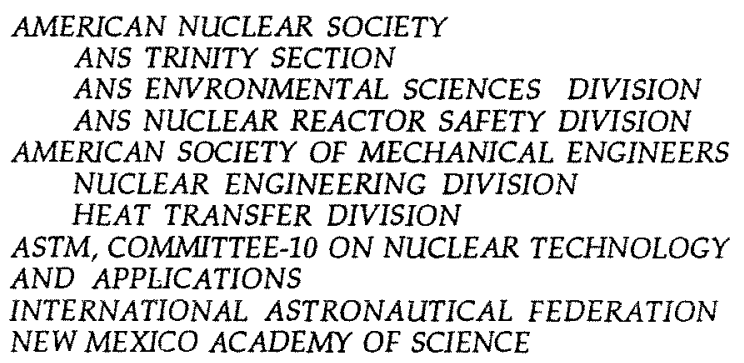

Industry Affiliates:

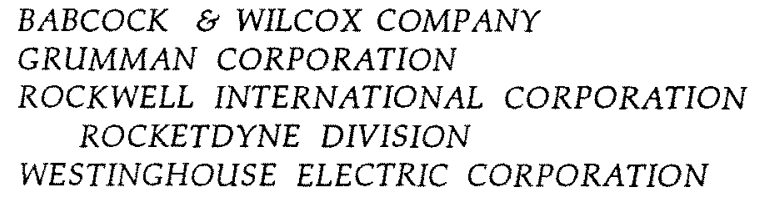
Albuquerque Convention Center
Albuquerque, New Mexico
January 12-16, 1992

